\title{
Epidemiology and aetiologies of hypopituitarism
}

Thierry Brue

Aix-Marseille University, Department of Endocrinology, Reference Center for Rare Pituitary Diseases, La Timone Hospital, Assistance Publique - Hospital de Marseille, Marseille, France

Centre de Recherche en Neurobiologie et Neurophysiologie de Marseille, France

\author{
Address for correspondence: \\ Thierry Brue \\ Service d'Endocrinologie \\ Hospital de la Timone \\ 264 rue Saint-Pierre \\ Marseille, France \\ E-mail: thierry.brue@univ-amu.fr
}

\section{Summary}

Anterior Pituitary Hormone Deficiencies may be due to any lesion in this anatomical region, most commonly benign tumors like pituitary adenomas or craniopharyngiomas, and to surgical or radiation-based treatments of these tumors. Less frequently, cranial traumas, inflammatory or autoimmune processes like lymphocytic hypophysitis or genetic defects may cause pituitary deficits. The resulting pituitary hormone deficiencies may lead to severe clinical consequences with significant morbidity and often increased mortality despite recent therapeutic improvements. The large observational studies launched for the follow-up of patients treated by growth hormone have provided valuable epidemiological data. In recent years, new aetiologies of acquired hypopituitarism have been reported such as hypophysitis following targeted anticancer immune therapies. Hypopituitarism however remains predominantly a consequence of benign pituitary tumors and of their treatments.

KEY WORDS: hypopituitarism; anterior pituitary hormone deficit; combined pituitary hormone deficiency; growth hormone; causes.

Anterior Pituitary Hormone Deficiencies may be secondary to any lesion in the sellar or suprasellar region, most commonly benign tumors like pituitary adenomas or craniopharyngiomas. Surgical or radiation-based treatments of these tumors are also a common cause of hypopituitarism. Less frequently, cranial traumas, inflammatory or autoimmune processes like lymphocytic hypophysitis may lead to pituitary deficits. Genetic causes may also result in congenital forms of combined pituitary hormone deficiencies (CPHD) or in isolated pituitary hormone deficiencies, such as isolated GH deficiency (1). New disease associations have been described, like the DAVID syndrome (Deficit in Anterior pituitary function and Variable Immuno-Deficiency) that we recently reported as an association of a deficit in adrenocorticotrophin, and possibly other anterior pituitary hormones, with recurrent infections due to variable immunodeficiency (2). In recent years, new aetiologies of acquired hypopituitarism have also been described such as the anti-Pit1 antibody syndrome (3), or hypophysitis following ipilimumab (anti-CTL4) therapy (4). Hypopituitarism however remains predominantly a consequence of benign pituitary tumors and of their treatments. These disorders represent a heterogeneous group of rare diseases leading to defective function of specific pituitary cell types. The resulting pituitary hormone deficiencies lead, if not treated in a timely fashion, to severe clinical consequences with significant morbidity and often increased standardized mortality ratios despite recent therapeutic improvements.

Pituitary deficiency is indeed associated with increased mortality predominantly due to vascular disease, which may be influenced by the disease that caused hypopituitarism, especially in case of longstanding cortisol or GH hypersecretion or of craniopharyngiomas, but also by the treatments of these conditions, especially radiotherapy. Replacement therapy is sometimes not optimal, leading to an additional risk of detrimental effects on outcome in patients with pituitary disease. The large observational studies that have been launched mainly for the follow-up of patients treated by growth hormone have provided valuable epidemiological data. For instance, the KIMS database (Pfizer International Metabolic Database) represents a large pharmaco-epidemiological follow-up database of over 13,000 adult patients with growth hormone deficiency (GHD). It shows that a number of different aetiologies account for hypopituitarism in these patients, but the great majority suffered from pituitary adenoma (44\%) and $11 \%$ of craniopharyngiomas. Idiopathic GHD was the reason for $\mathrm{GH}$ replacement in $16 \%$, brain tumor or cranial irradiation in $7 \%$, and traumatic brain injury or Sheehan's syndrome each in about 3\% (5). The incidence of some classical causes of hypopituitarism such as Sheehan's syndrome has dramatically dropped with the improvement of obstetrical management standards in many countries, explaining why this aetiology has become an overlooked cause in developed countries (6). 
Pituitary insufficiency is also a therapeutic challenge, as all deficient anterior pituitary hormones, maybe with the exception of prolactin, require optimal replacement therapy while this goal is hardly obtained by currently available treatments. A better knowledge of pituitary development and of pituitary stem cells that have recently been identified in this gland may however pave the way for better treatment modalities in the future (7). This represents a challenge which is all the more relevant for the future management of hypopituitarism as recent studies have confirmed the increased mortality associated with this condition (8).

\section{References}

1. Castinetti F, Reynaud R, Saveanu A, Barlier A, Brue T. Genetic causes of combined pituitary hormone deficiencies in humans. Ann Endocrinol (Paris) 2012 Apr; 73(2):53-5.

2. Quentien MH, Delemer B, Papadimitriou DT, Souchon PF, Jaussaud $R$, Pagnier A,Munzer M, Jullien N, Reynaud R, Galon-Faure N, Enjalbert A, Barlier A, Brue T. Deficit in anterior pituitary function and variable immune deficiency (DAVID) in children presenting with adrenocorticotropin deficiency and severe infections. J Clin Endocrinol Metab 2012 Jan; 97(1):E121-8.

3. Yamamoto $M$, Iguchi $G$, Takeno $R$, Okimura $Y$, Sano T, Takahashi M, Nishizawa $H$, Handayaningshi AE, Fukuoka H, Tobita M, Saitoh T, Tojo K, Mokubo A,
Morinobu A, lida K, Kaji H, Seino S, Chihara K, Takahashi Y. Adult combined $\mathrm{GH}$, prolactin, and TSH deficiency associated with circulating PIT-1 antibody in humans. J Clin Invest 2011 Jan; 121(1):113-9.

4. Juszczak A, Gupta A, Karavitaki N, Middleton MR, Grossman AB. Ipilimumab: a novel immunomodulating therapy causing autoimmune hypophysitis: a case report and review. Eur J Endocrinol $2012 \mathrm{Jul}$; 167(1):1-5.

5. Brabant G, Poll EM, Jönsson P, Polydorou D, Kreitschmann-Andermahr I. Etiology, baseline characteristics, and biochemical diagnosis of $\mathrm{GH}$ deficiency in the adult: are there regional variations? Eur J Endocrinol 2009 Nov; 161 Suppl 1:S25-31.

6. Ramiandrasoa C, Castinetti F, Raingeard I, Fenichel $\mathrm{P}$, Chabre O, Brue T, Courbière B. Delayed diagnosis of Sheehan's syndrome in a developed country: a retrospective cohort study. Eur J Endocrinol 2013 Sep 12; 169(4):431-8.

7. Castinetti F, Davis SW, Brue T, Camper SA. Pituitary stem cell update and potential implications for treating hypopituitarism. Endocr Rev 2011Aug; 32(4):45371.

8. Burman P, Mattsson AF, Johannsson G, Höybye C, Holmer H, Dahlqvist P, BerinderK, Engström BE, Ekman B, Erfurth EM, Svensson J, Wahlberg J, Karlsson FA. Deaths among adult patients with hypopituitarism: hypocortisolism during acute stress, and de novo malignant brain tumors contribute to an increased mortality. J Clin Endocrinol Metab 2013 Apr; 98(4):1466-75. 